\title{
Have mortality improvements stalled in England?
}

\author{
Same data-different stories
}

\author{
Mark Fransham researcher and DPhil candidate, Danny Dorling Halford Mackinder professor of \\ geography
}

School of Geography and the Environment, University of Oxford, South Parks Road, Oxford OX1 3QY, UK

From 2014 to 2015 the number of deaths in England and Wales rose by $5.6 \%$ (by 28000 to 530000 in 2015), the largest percentage year on year increase since $1968 .{ }^{1}$ US life expectancy started to fall in 2016, which was attributed to declining access to healthcare for poorer Americans and wider societal factors. ${ }^{2}$ For middle aged Americans, death rates have not improved in almost 20 years, owing to "a lack of hope."3

On 6 April 2017 the UK Office for National Statistics released an analysis of deaths in England from January 2001 to the end of December 2016. ${ }^{4}$ It said that fewer deaths were registered in 2016 (491000) than in 2015 and that the death rate in 2016 (958.0 deaths per 100000 population) was the second lowest since 2001. Life expectancy in 2016 was higher than in 2015, and the number of deaths in 2016 was lower than expected based on the average death rate between 2011 and 2015 (973.3 per 100000 ). Death rates have fallen among people aged over 75 since 2001, by almost a third for those aged 75 to 79, but "most of the fall was up to 2011, and there has been little change since then" (fig 1).

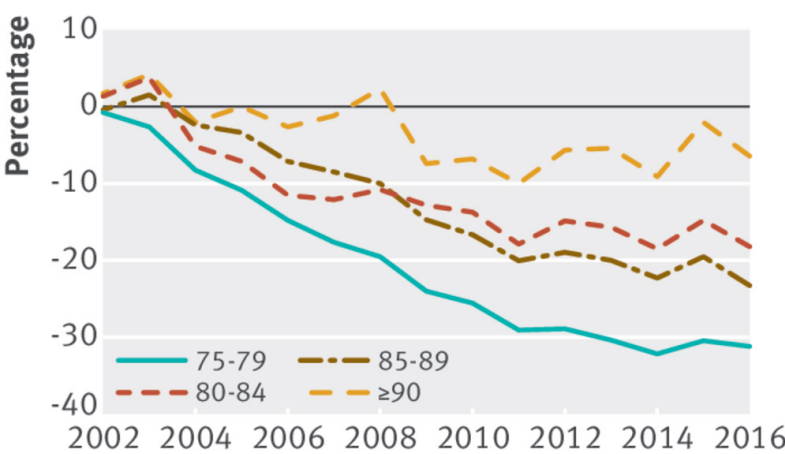

Year

Fig 1 Difference in mortality rates compared with 2001 in those aged 75 and over, 2002 to 2016. Source: UK Office for National Statistics. ${ }^{4}$

\section{A different story}

Ten days earlier the Institute and Faculty of Actuaries published the latest version of its mortality model, concluding that mortality had not improved since 2011 and that death rates for women were slightly higher in 2016 than in $2011 .{ }^{5}$ Between 2000 and 2011 mortality (calculated for those aged 20 years and above) improved at an average trend rate of $2.2 \%$ a year for women (from 1375 to 1080 per 100000 ) and $2.6 \%$ for men (from 2033 to 1511), but in 2016 it was 1089 for women and 1485 for men. This is $11 \%$ higher than would have been expected (983 for women and 1331 for men) if the earlier improving trend from 2001 to 2011 had continued (fig 2).

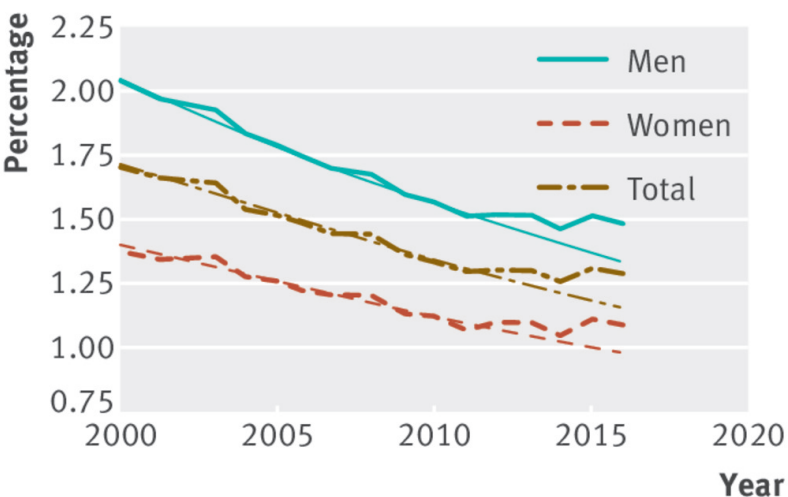

Fig 2 Standardised mortality ratios for people aged 20 to 100 years (solid lines) and trends (dashed) 2000-11. Source: Continuous Mortality Investigation. ${ }^{5}$

Partly because of these mortality trends and partly because of changes in the model, cohort life expectancy-that is, the average life expectancy given the projections of future mortality rates-for women aged 65 years in January 2017 is 24.1 years, $2 \%$ lower than the institute's earlier estimation of 24.6 years. The actuaries concluded that recent mortality improvements might be the result of medium or long term influences, rather than short term events such as influenza in early $2015 .^{5}$ 
These apparently divergent conclusions might be explained by differences in analysis and presentation. The Institute and Faculty of Actuaries conducted a trend analysis, identifying 2011 as the year when the trend in mortality changed direction, whereas the Office for National Statistics compared death rates in 2016 with those in arbitrarily chosen years-mostly 2001 and 2015. The particularly high number of deaths in 2015 might have skewed the results, giving the impression of improvement when actually death rates have not fallen for five years.

\section{Possible explanations}

Untangling the reasons for stalled improvements in mortality will be difficult. Potential explanations include the crisis in healthcare and social care ${ }^{1}$ and reduced spending on benefits for pensioners on low incomes. ${ }^{6}$ Pensioner poverty has mirrored changes in mortality, falling from $29 \%$ in 1997 to $13 \%$ in 2011 and remaining unchanged. ${ }^{7}$ Short term influences, such as influenza, have been posited but discarded as explanations for this longer term change to mortality trends. ${ }^{8}$

The stagnation of death rates that began in 2011 coincided with a radical change to public policy-the newly imposed austerity policies of the coalition government. This is a plausible cause that ought to be investigated by public health officials responsible for monitoring and improving the health of the nation. The Office for National Statistics produced its report "with support from Public Health England," a government agency that has yet to recognise the change that occurred after $2010 .^{10}$

\section{The importance of death rates}

Death rates matter because they tell us about the health of our society and provide information on which decisions are made. The actuaries' figures are used to calculate the pensions that they will pay out in the future. After its release national newspapers reported that $£ 28$ bn ( $€ 33 \mathrm{bn}$; $\$ 36 \mathrm{bn}$ ) had been wiped off the pension liabilities of FTSE 350 companies. ${ }^{8}$ The stalling of mortality improvement could mean that final salary pension schemes closed to new members due to being unaffordable for companies could have been affordable after all. ${ }^{11}$
These new data show that under David Cameron and Theresa May rising mortality rates have stalled; progress is at its worst since the end of the Second World War. The response from policy makers has been non-existent. Until our statisticians and demographers get their facts straight, there is nothing to respond to. If the causes of stagnating mortality are amenable to changes in healthcare and social policy, the cost of this institutional lack of curiosity could be measured not only in the billions of pounds wiped off the values of pensions, but in years of life lost to millions of people.

Provenance: Not commissioned, not peer reviewed.

Competing interests: The authors have read and understood BMJ policy on declaration of interests and have no relevant interests to declare.

1 Hiam L, Dorling D, Harrison D, McKee M. What caused the spike in mortality in England and Wales in January 2015? J R Soc Med 2017;110:131-7. http://journals.sagepub.com/ doi/10.1177/0141076817693600. doi:10.1177/0141076817693600 pmid:28208024.

2 Bernstein L. US life expectancy declines for the first time since 1993. Washington Post 2016 Dec 8. www.washingtonpost.com/national/health-science/us-life-expectancy-declinesfor-the-first-time-since-1993/2016/12/07/7dcdc7b4-bc93-11e6-91ee-1adddfe36cbe_story. $\mathrm{html}$

3 Guo J. The disease killing white Americans goes way deeper than opioids. Washington Post 2017 Mar 24. www.washingtonpost.com/news/wonk/wp/2017/03/24/the-diseasekilling-white-americans-goes-way-deeper-than-opioids/

4 Office for National Statistics. Quarterly mortality reports, England: data up to December 2016. Newport: Office for National Statistics, 2017. www.ons.gov.uk/releases/ quarterlymortalityreportsdatauptodec2016

5 Investigation CM. CMI mortality projections model CMI_2016. Mortality projections committee working paper 97. https://www.actuaries.org.uk/learn-and-develop/continuousmortality-investigation/cmi-working-papers/mortality-projections/cmi-working-papers-9798-and-99

6 Loopstra R, McKee M, Katikireddi SV, Taylor-Robinson D, Barr B, Stuckler D. Austerity and old-age mortality in England: a longitudinal cross-local area analysis, 2007-2013. J R Soc Med 2016;109:109-16. doi:10.1177/0141076816632215 pmid:26980412.

7 Belfield C, Cribb J, Hood A, Joyce R. Living standards, poverty and inequality in the UK: 2016. Institute for Fiscal Studies, 2016.

8 Knapton S. Flu jab blunder brought unexpected benefits for Britain's pension black hole. Telegraph 2017; 29 March 29. www.telegraph.co.uk/science/2017/03/29/flu-jab-blunderbrought-unexpected-benefits-britains-pension/

9 Deaths in the UK have risen by more than 40000 per annum since 2011. Why? Exploring the causes of increasing mortality. 2020 Delivery 2017 Jan 11. www.2020delivery.com/ news/2017-mortality-analysis/

10 Britain's long-falling death rate has levelled out. A blip or something more? Economist 2017; 16 March. www.economist.com/news/britain/21718939-2015-saw-biggest-annualleap-deaths-50-years-britains-long-falling-death-rate-has

11 Hilton A. If the rise in life expectancy is starting to stall, expect pension shockwaves. Evening Standard 2015; 16 September. www.standard.co.uk/business/anthony-hilton-ifthe-rise-in-life-expectancy-is-starting-to-stall-expect-pension-shockwaves-a2949051.html

Published by the BMJ Publishing Group Limited. For permission to use (where not already granted under a licence) please go to http://group.bmj.com/group/rights-licensing/ permissions 